\title{
latrogenic Rectal Diverticulum With Pelvic-Floor Dysfunction in Patients After a Procedure for a Prolapsed Hemorrhoid
}

\author{
Sun Kyung Na, Hye-Kyung Jung, Ki-Nam Shim, Sung-Ae Jung, Soon Sup Chung ${ }^{1}$ \\ Department of Internal Medicine, Ewha Womans University College of Medicine, Seoul; ${ }^{1}$ Department of Surgery, Ewha Womans University \\ College of Medicine, Seoul, Korea
}

Diverticula are frequently seen in the sigmoid, descending, ascending and transverse colons whereas rectal diverticula are extremely rare. The stapled rectal mucosectomy for the treatment of a prolapsed hemorrhoid is less painful and has lower morbidity; therefore, it has been commonly used despite possible complications. This paper reports a case of a rectal diverticulum that developed after a procedure for prolapsed hemorrhoids (PPH). A 42-year-old man with a history of hemorrhoidectomies came to the hospital because of constipation. On sigmoidoscopy, a 2-cm-sized, feces-filled pocket was located just above the anorectal junction. After removal of the fecal material, a huge rectal diverticulum $(-4 \mathrm{~cm}$ in diameter) was seen. Pelvic magnetic resonance imaging (MRI) confirmed the diagnosis of rectal diverticulum outpouching through the muscular layer of the intestine in a left posterolateral direction. The patient was discharged without complication after a transanal diverticulectomy had been performed, and the direct rectal wall had been repaired.

\section{Keywords: Diverticulum; Prolapsed hemorrhoids; Hemorrhoidectomy}

\section{INTRODUCTION}

The transanal stapled technique has been recently used as an effective, low-morbidity operation for the treatment of prolapsed hemorrhoids. Moreover, a recent systematic review concluded that a stapled rectal mucosectomy is a less painful method and is more convenient for the surgeon, though it carries more recurrences and unique potential complications [1]. Among them, a rectal diverticulum is a rare, but possible, complication. The aim of this case study was to demonstrate the possibility of a rectal diverticulum developing in patients with hemorrhoids who were treated using endoanal circular staplers. We report a case of a sus-

Received: June 19,2013 - Accepted: September 9, 2013

Correspondence to: Hye-Kyung Jung, M.D.

Digestive Disease Center, Ewha Womans University Mokdong Hospital,

1071 Anyangcheon-ro, Yangcheon-gu, Seoul 158-710, Korea

TEL: +82-2-2650-5890, Fax: +82-2-2655-2076

E-mail: junghk@ewha.ac.kr

(C) 2014 The Korean Society of Coloproctology

This is an open-access article distributed under the terms of the Creative Commons Attribution NonCommercial License (http://creativecommons.org/licenses/by-nc/3.0) which permits unrestricted non-

commercial use, distribution, and reproduction in any medium, provided the original work is properly cited. picious iatrogenic rectal diverticulum after a procedure for prolapsed hemorrhoids (PPH).

\section{CASE REPORT}

A 42-year-old man with a 4-month history of constipation came to the hospital. The patient complained of excessive effort for evacuation, unsuccessful attempts, and long periods spent in the bathroom. Medical history included a hemorrhoidectomy four years earlier. He is a current smoker with a smoking history of 10 packs/yr.

A review of the symptoms showed no abnormality, except constipation. Physical examination revealed normal rectal tone and intact anorectal inhibitory reflex. Laboratory findings showed no specific abnormality. On sigmoidoscopy, a feces-filled pocket with a 2-cm-sized opening was located just above the anorectal junction (Fig. 1A). After the fecal material had been removed by using forceps, which took about one hour, a huge rectal diverticulum was seen (Fig. 1B). The rectal mucosa surrounding the saccular lesion was normal, except for mild hyperemia and edema. There was no evidence of a fistula. The colon transit time was in the normal range (Table 1), and anorectal manometry showed a reversed 

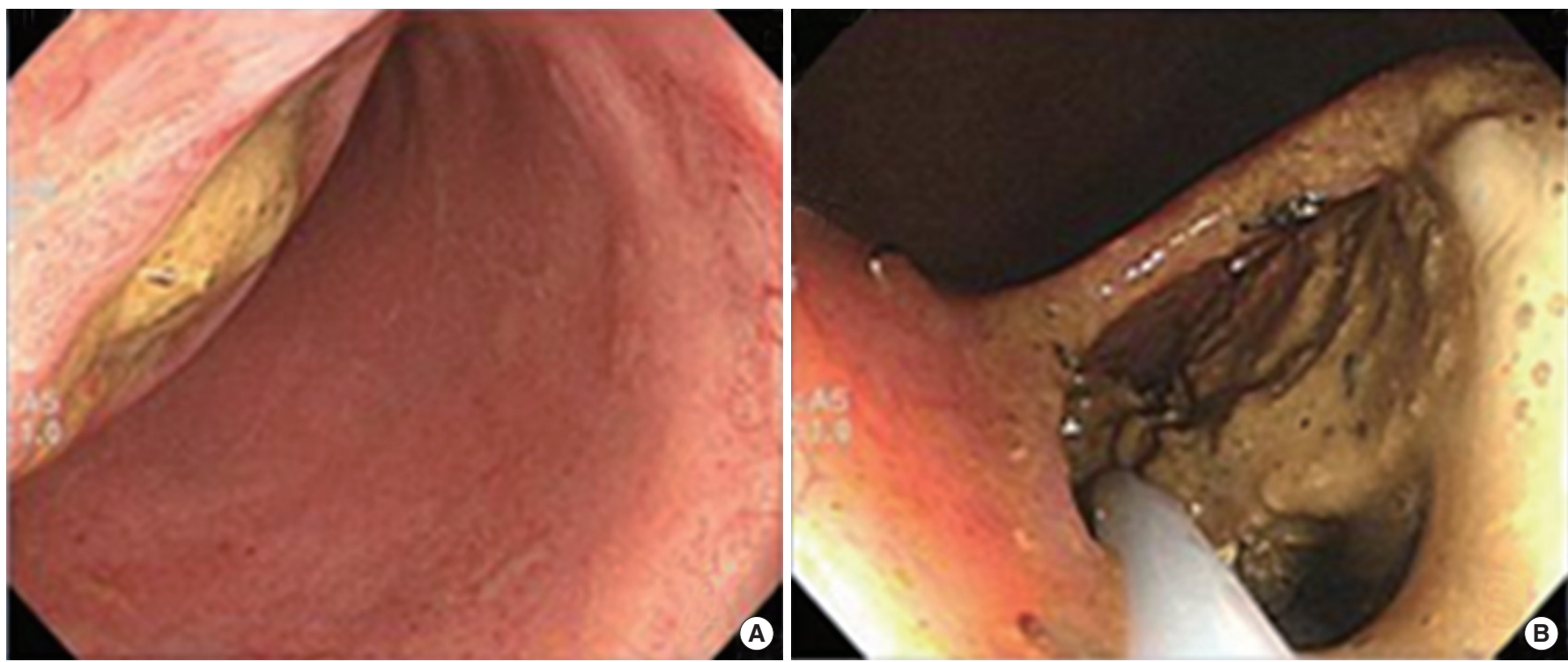

Fig. 1. Sigmoidoscopy at diagnosis. (A) The pocket was located just above the anorectal junction and was filled with feces. (B) After removal of the fecal material, a huge rectal diverticulum was seen.

Table 1. Colon transit time

\begin{tabular}{lcccc}
\hline & \multicolumn{4}{c}{ No. of markers present } \\
\cline { 2 - 5 } & Right colon & Left colon & Rectosigmoid & Total colon \\
\hline 4th Day & 6 & 19 & 14 & 39 \\
7th Day & 0 & 0 & 0 & 0 \\
Total & 6 & 19 & 14 & 39 \\
\hline
\end{tabular}

There was no passage disturbance.

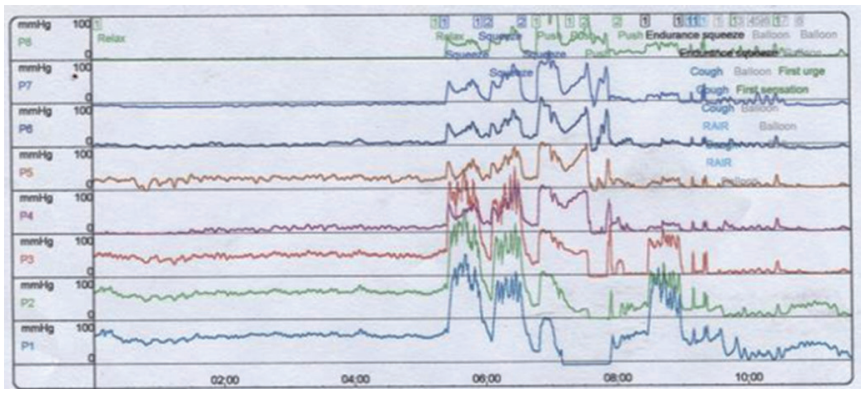

Fig. 2. Rectal manometry at diagnosis; defecation index $=0.9$, rectal and anal pressure were elevated (pelvic-floor dysfunction, type 1).

defecation index with increased anal and rectal pressure at straining, consistent with pelvic floor dysfunction, type I (Fig. 2). Defecography showed a filled defect with a broad base at the anterior wall of the rectum, leading to lumen narrowing. These findings seemed to be associated with the excessive effort for evacuation (Fig. 3). Pelvic magnetic resonance imaging confirmed the diagnosis of rectal diverticulum outpouching through the muscular layer of the intestine in the left posterolateral direction (Fig. 4).

As a huge rectal diverticulum with fecalith can cause severe in-

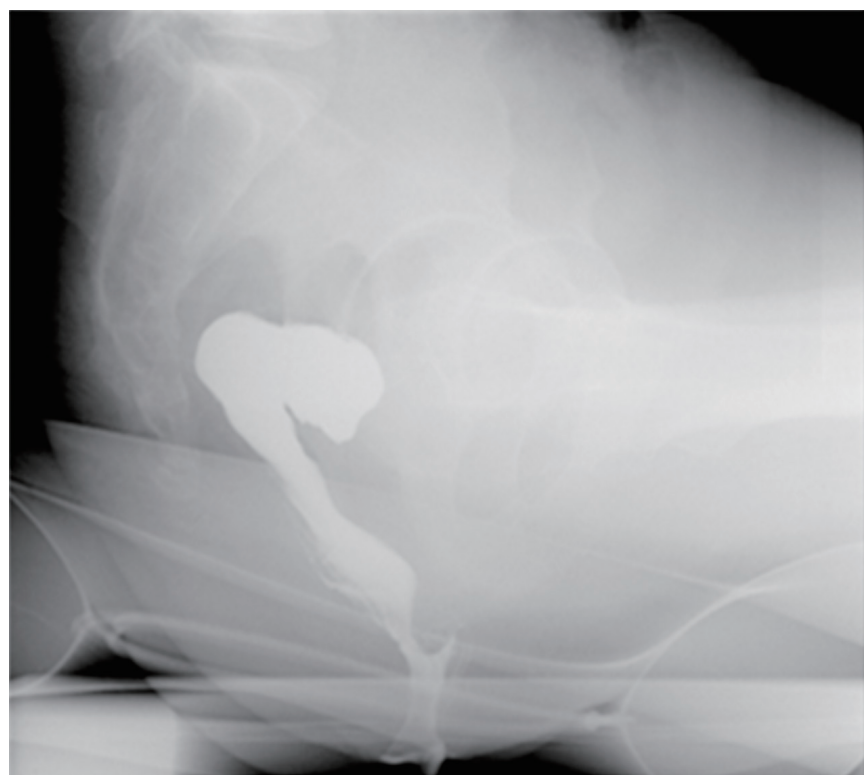

Fig. 3. Defecography showed the filling defect with broad base at anterior wall of rectum leads to lumen narrowing.

flammation or sepsis, we decided to perform surgery. The patient underwent a transanal diverticulectomy and a direct rectal-wall repair. After the operation, the chief complaint, constipation, was lessened. He was discharged without any complications from the surgery and with no remaining symptoms. At the two-month follow-up, no abnormalities, except for a minimal saccular lesion, were found on sigmoidoscopy. 

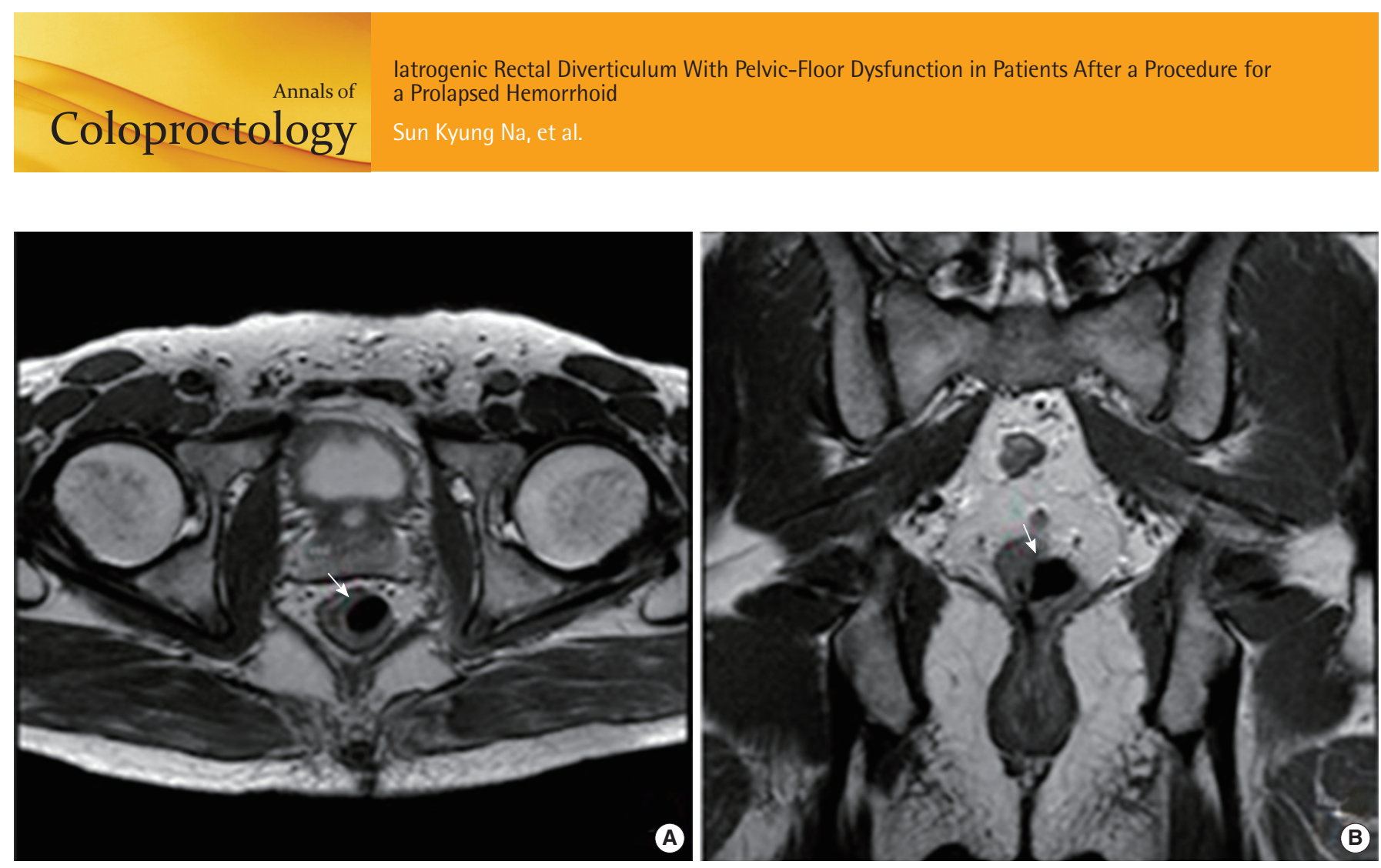

Fig. 4. The transverse (A) and the coronal (B) images on pelvic magnetic resonance imaging showed a rectal diverticulum outpouching through the muscular layer of the intestine (arrow).

\section{DISCUSSION}

Colonic diverticula are acquired herniations of the mucosa and part of the submucosa through the muscularis propria. Diverticula are more frequently seen in the sigmoid colon (90\%), descending colon (30\%), and transverse colon (16\%) whereas rectal diverticula are extremely rare, with an estimated frequency of less than $0.1 \%$ of the cases of colonic diverticular disease. As the taeniae coalesce at the rectum to form a circumferential support lining at the rectal level, a rectal diverticulum is a very rare occurrence. A diverticulum may, however, arise at a point where the rectal wall has a focal weakness due to congenital or acquired causes [2]. Possible predisposing factors for acquired causes include recurrent fecal impaction with increased pressure and rectal distension, pelvic trauma, and infections causing a weakening of the rectal wall. Typically, diverticulum are located along the lateral walls of the rectum, as the longitudinal layer tends to be thicker at anterior and posterior locations than at lateral locations [3]. Although the factors contributing to the development of the rectal diverticulum have not been completely elucidated in this case, focal weakness at the point of surgery should be considered in determining the cause.

For several years now, the use of mechanical suturing devices (staplers) has become common for treating hemorrhoidal disease. The whole procedure with this device is performed within the insensate area of the rectum above the dentate line. Therefore, it is less painful and shortens the admission period after surgery. The mucosa to be removed is prepared with purse-string sutures [4-8]. Special care must be taken at this step to suture the mucosa only, as deeper sutures will cut the muscular fibers [9]. Thus, a possible hypothesis is that a focal weakness of the rectal wall develops as a result of tears or the absence of the muscular lining, which may constitute points of least resistance and, therefore, become a predisposing factor for the development of a rectal diverticulum.

Rectal diverticula require no treatment and are asymptomatic in the majority of patients. Occasionally, a rectal diverticulum may become inflamed with impacted feces and be associated with perforation and abscess formation [10]. In addition, a rectal prolapse due to an inverted rectal diverticulum, rectal stenosis, or rectovesical fistula is possible. Surgery becomes necessary in the event of complications. In the present case, a huge diverticulum cavity of the rectum became the cause of fecal impaction, which can cause inflammation and worsen constipation.

The development of a rectal diverticulum is an unexpected event, and practitioners should be aware of this complication as it may cause other symptoms. Its prevalence is likely underestimated as it is often asymptomatic in the short term; however, the effects of a long-term evolution are unknown. Recognizing a rectal diverticulum as a possible consequence of a $\mathrm{PPH}$ is important for correct identification and interpretation of abnormal colonoscopic findings and possible treatment planning. Even if the diverticulum does not cause any symptomes, a transanal operation should be considered as the diverticulum may be associated with complication.

\section{CONFLICT OF INTEREST}

No potential conflict of interest relevant to this article was reported. 


\section{REFERENCES}

1. Nisar PJ, Acheson AG, Neal KR, Scholefield JH. Stapled hemorrhoidopexy compared with conventional hemorrhoidectomy: systematic review of randomized, controlled trials. Dis Colon Rectum 2004;47:1837-45.

2. Gore RM, Levine MS, Laufer I. Textbook of gastrointestinal radiology. Philadelphia: WB Saunders; 1994.

3. Alabiso ME, Grassi R, Fioroni C, Marano I. Iatrogenic rectal diverticulum in patients treated with transanal stapled techniques. Radiol Med 2008;113:887-94.

4. Pessaux P, Tuech JJ, Arnaud JP. Hemorroidectomy by circular anopexia. The Longo technique. J Chir (Paris) 2001;138:222-5.

5. Rowsell M, Bello M, Hemingway DM. Circumferential mucosectomy (stapled haemorrhoidectomy) versus conventional haemorrhoidectomy: randomised controlled trial. Lancet 2000;355:779-
81.

6. Wilson MS, Pope V, Doran HE, Fearn SJ, Brough WA. Objective comparison of stapled anopexy and open hemorrhoidectomy: a randomized, controlled trial. Dis Colon Rectum 2002;45:1437-44.

7. Hetzer FH, Demartines N, Handschin AE, Clavien PA. Stapled vs excision hemorrhoidectomy: long-term results of a prospective randomized trial. Arch Surg 2002;137:337-40.

8. Gravie JF, Lehur PA, Huten N, Papillon M, Fantoli M, Descottes B, et al. Stapled hemorrhoidopexy versus milligan-morgan hemorrhoidectomy: a prospective, randomized, multicenter trial with 2-year postoperative follow up. Ann Surg 2005;242:29-35.

9. Oughriss M, Yver R, Faucheron JL. Complications of stapled hemorrhoidectomy: a French multicentric study. Gastroenterol Clin Biol 2005;29:429-33.

10. Piercy KT, Timaran C, Akin H. Rectal diverticula: report of a case and review of the literature. Dis Colon Rectum 2002;45:1116-7. 